\title{
Singlet oxygen production by a polypyridine ruthenium (II) complex with a perylene monoimide derivative: A strategy for photodynamic inactivation of Candida albicans
}

\author{
Paulo José Sousa Maia a,b,d,*, Inara de Aguiar ${ }^{b}$, Marisol dos Santos Velloso ${ }^{c}$, Dong Zhang ${ }^{\mathrm{d}}$, \\ Edjane Rocha dos Santos ${ }^{\mathrm{b}}$, Jonatas Rafael de Oliveira ${ }^{\mathrm{c}}$, Juliana Campos Junqueira ${ }^{\mathrm{c}}$, \\ Matthias Selke ${ }^{\mathrm{d}, * *}$, Rose Maria Carlos ${ }^{\mathrm{b}}$ \\ a Institute of Exact Sciences and Technology, Federal University of Amazonas, 69103-128, Itacoatiara, AM, Brazil \\ ${ }^{\mathrm{b}}$ Department of Chemistry, Universidade Federal de São Carlos, CP 676, 13565-905, São Carlos, SP, Brazil \\ ${ }^{\mathrm{c}}$ Department of Biosciences and Oral Diagnosis, Universidade Estadual Paulista/UNESP, Av. Engenheiro Francisco José Longo, 777, 12245-000, São José dos \\ Campos, SP, Brazil \\ d Department of Chemistry and Biochemistry, California State University, 90032, Los Angeles, CA, United States
}

\section{A R T I C L E I N F O}

\section{Article history:}

Received 16 November 2017

Received in revised form 10 December 2017

Accepted 12 December 2017

Available online 13 December 2017

\section{Keywords:}

Singlet oxygen

Photodynamic therapy (PDT)

Candida albicans

Ruthenium polypyridine complex

Photoluminescence

\section{A B S T R A C T}

We report the synthesis, optical, electrochemical and electronic properties of a new perylene derivative and its $\mathrm{Ru}(\mathrm{II})$ complex, namely $\mathrm{N},-(5$-amino-1,10-phenantroline)perylene-3,4,9,10-tetracarboximonoimide (pPDI) and $\operatorname{Bis}(1,10$-phenanthroline)(N-(5-amin-1,10-phenantroline)perylene-3,4,9,10-tetracarboxi monoimide)ruthenium(II) hexafluorophosphate, $\left[\mathrm{Ru}(\mathrm{phen})_{2}(\mathrm{PPDI})\right]^{2+}\left(\left[\mathrm{PF}_{6}\right]^{-}\right)_{2}$. The molecular structures of the compounds were elucidated by FTIR, mass spectrometry, elemental analysis (CHN) and DFT calculations. Their optical and electrochemical properties were investigated by absorption and fluorescence spectroscopy and cyclic voltammetry. The spectroscopic and electrochemical studies for both the pPDI and the perylene monoimide metal complex show that $\mathrm{Ru}^{2+}$ coordination does not affect the optical and electrochemical properties of the free perylene bisimide ligand. The Ru complex exhibits emission lifetimes of $5.06 \mathrm{~ns}$ (48.1\%) and $156 \mathrm{~ns}$ (51.9\%), resulting from emission of the pPDI ligand and ${ }^{3} \mathrm{MLCT}$, respectively. The pPDI triplet excited state in the title chromophore is able to sensitize the production of singlet oxygen $\left({ }^{1} \mathrm{O}_{2}\right)$. Using a time-resolved laser system, we measured the quantum yield for the production of singlet oxygen $(\Phi \Delta)$ to be 0.26 for cis-[Ru(phen $\left.)_{2}(\mathrm{pPDI})\right]^{2+}$. Candida albicans is recognized as the most common fungal pathogens, causing superficial infections of the skin and mucous membranes. Resistance of $C$. albicans strains against classical antifungal agents such as fluconazole has increased considerably, which drives the search for new therapeutic alternatives. In the present study, we report that our new Ru-perylene complex can indeed be used to kill the bacterium $C$. albicans. The fungicidal activity of cis-[Ru(phen $\left.)_{2}(\mathrm{pPDI})\right]^{2+}$ against $C$. albicans was evaluated in the presence of $C$. albicans cultures in the dark and in the presence of light. After exposure to $12.5 \mu \mathrm{M}$ of cis-[Ru (phen $\left.)_{2}(\mathrm{pPDI})\right]^{2}$ in the presence of light for $180 \mathrm{~s}$, C. albicans showed a decrease of $50 \%$ in its concentration compared to the same experimental conditions in the dark.

(c) 2017 Elsevier B.V. All rights reserved.

\section{Introduction}

Singlet oxygen $\left({ }^{1} \mathrm{O}_{2},{ }^{1} \Delta_{\mathrm{g}}\right)$, the lowest excited state of the dioxygen molecule, can be generated by photochemical and

\footnotetext{
* Corresponding author at: Department of Chemistry, Universidade Federal de São Carlos, CP 676, 13565-905, São Carlos, SP, Brazil.

** Corresponding author.

E-mail addresses: pmldcb@gmail.com (P.J.S. Maia), mselke@calstatela.edu (M. Selke).
}

chemical processes [1-6]. The most common photochemical method involves energy transfer from a triplet excited photosensitizer $\left({ }^{3 *} \mathrm{PS}\right)$. Many dyes, including some diimides [2-4] and metal complexes[3-10] can be used as photosensitizers for the production of ${ }^{1} \mathrm{O}_{2}$.

A variety of transition metal complexes have been studied as photosensitizers for singlet oxygen generation [2,5-8]. Amongst these complexes, $\mathrm{Ru}(\mathrm{II})$-polypiridyl complexes have been investigated due to their stability, inertness and biological activity [7-10]. These complexes have long emission lifetimes from the triplet 
metal-to-ligand charge transfer state $\left({ }^{3} \mathrm{MLCT}\right)\left(\mathrm{d} \pi \rightarrow \pi^{*}, \alpha\right.$-diimine states) [11]. This state is rapidly quenched by triplet (ground state) dioxygen, which makes many Ru(II)-polypiridyl complexes both efficient oxygen sensors and singlet oxygen sensitizers [710,12]. For example, Demas and co-workers analyzed the oxygen quenching by Ru (II), Os (II) and Ir (III) polypiridyl complexes containing bipyridine, 1,10-phenanthroline and/or phenanthroline diimines $[8,13]$. These complexes have shown high quantum yields for singlet oxygen formation, with values of $\Phi \Delta$ ranging from 0.68 0.86 .

Upon excitation of $\mathrm{Ru}$ (II) complexes, singlet excited states of the ligand and the ${ }^{1} \mathrm{MLCT}$ state $\mathrm{d}_{\mathrm{Ru}} \rightarrow \pi^{*}{ }_{\mathrm{L}}$ are initially formed. From these states, intersystem crossing to the ${ }^{3}$ MLCT state takes place, which is responsible for the luminescence of $\mathrm{Ru}$ (II) complexes. Therefore, to modulate and increase the absorption and emission properties of $\mathrm{Ru}(\mathrm{II})$ complexes, molecular engineering of its ligands has been attempted [14].

However, Ru complexes with mixed ligands showed much lower triplet lifetimes. This is due to the increase in conjugation, which results in the availability of lower excited state energy levels for non-radiative deactivation of the ${ }^{3}$ MLCT state. Complexes where the ligand is substituted with an aryl group in the 5-position were found to have longer excited-state lifetimes and were the most efficient photosensitizers [15]. Substituted ethoxybenzene or vinyl-linked benzocrown-ether-2,2-bipyridine $\mathrm{Ru}(\mathrm{II})$ complexes have also been tested for their singlet oxygen production ability, and their quantum yields are in the range of $0.18-0.47$ [13]. A series of aza-15-crown-5-vinyl-2,2-bipyridine $\mathrm{Ru}(\mathrm{II})$ complexes and multinuclear $\mathrm{Ru}(\mathrm{II})$ complexes were investigated by Abdel-Shafi et al. and these polypyridine complexes had quantum yields that ranged from 0.21 to 0.54 [13].

For many large-scale photochemical processes, it would be desirable to employ photosensitizers that show strong absorption of radiation in the visible region, ideally near the solar maximum. The absorption spectra of the perylene complexes, in general, do show a high absorption coefficient in the visible region. Thus, such complexes could potentially be used for photochemical processes initiated by sunlight. This might include generation of singlet oxygen, and subsequent pollutant degradation and photodynamic activity $[7,10,15]$. A number of perylene-3,4,9,10-tetracarboxylic acid (diimide) derivatives, known as PDIs, and polypyridine complexes derived from perylenes have shown good results in the production of reactive species of reactive oxygen species (ROS) [11,16-18]. The ligands containing the perylene moiety are reddish dyes with very high quantum yields of luminescence. However, an undesired property of perylene complexes is the formation of molecular aggregates, which is facilitated by the flatness of the perylene molecules $[19,20]$.
The perylene dyes are known for their poor solubility in organic solvents (typically $1-2 \mathrm{mg} \mathrm{L}^{-1}$ ) $[11,21,22]$. Their PDI diimide derivatives with symmetrical and unsymmetrical secondary, or tertiary alkyl side chains N,N'-bis(1-isobutyl-3 methylbutyl) perylene-3,4:9,10-bis(dicarboximide), N,N'-bis(1-butylhexyl)perylene-3,4:9,10-bis(dicarboximide) and N,N'-bis(5-tert-butyl1,3,4-thiadiazole-2-yl)perylene-3,4:9, 10-bis(dicarboximide) were synthesized and had significantly improved solubility $(10 \mathrm{mg} / \mathrm{mL})$ in dichloromethane, chloroform, ether, hexane, chlorobenzene and toluene [16,17]. Single or double amine substitution on the perylene core can also lead to a red shift of the absorption maximum up to $750 \mathrm{~nm}[11,22,23]$.

Recently, Santos and co-wokers [11] synthesized the complex cis-[(phen)2Ru(pPDIp)]2+, where pPDIp is a perylene diimine group functionalized with phenanthroline ligands where one side is coordinated to a $\mathrm{Ru}(\mathrm{II})$ center. The complex shows strong electronic absorption bands attributed to the pPDIp and $\{\mathrm{Ru}(\mathrm{phen})$ $2\}^{2+}$ moieties in acetonitrile. The charge-separated intermediate species decays to generate the triplet state ${ }^{3 *}$ pPDIpRu(II) $(\tau \mathrm{P}=1.8 \mu \mathrm{s})$ that sensitizes the formation of singlet molecular oxygen with quantum yield $\Phi_{\Delta}=0.57$. The electronic coupling between the pPDI ligand and the $\mathrm{Ru}(\mathrm{II})$-polypyridine unit was assigned to allow the population of the triplet ${ }^{3^{*}} \mathrm{PDI}$ excited states from the ${ }^{3^{*}}$ MLCT emitter state, generating an excited state $\left\{(\text { Phen })_{2} \mathrm{Ru}^{3+}\left(\mathrm{PPDIP}^{--}\right)\right\}$. It is important to note that the rigid structure of the complex unit $\left\{\mathrm{Ru}(\mathrm{phen})_{3}\right\}^{2+}$ with strong coordination of the ligand field leads to the stability of the complex avoiding its photodissociation. These studies exemplify how molecular engineering of the ligands is relevant to be used to modulate the photophysical behavior of the ligands coordinated to the $\mathrm{Ru}(\mathrm{II})$.

The high extinction coefficients, ease of triplet formation, and absorption in the visible range make the perylene complexes good candidates for singlet oxygen sensitizers. Given their high extinction coefficients in the visible range, they can be potentially used as candidates in the field of photodynamic inactivation of microorganisms, against cancer cells and pathogenic microorganisms. Several groups have investigated Ru(II) complexes for their photodynamic activity. Akkaya et al. have synthesized a series of water-soluble green perylenediimide (PDI) dyes. Upon excitation with red light, these dyes were shown to be efficient generators of singlet oxygen, and in cell culture media, they were shown to display significant light-induced cytotoxic effects on the human erythroleukemia cell line (K-562) [24].

In the present study, we prepared a new polypyridine complex of ruthenium cis-[Ru(phen $\left.)_{2}(\mathrm{pPDI})\right]^{2+}$, where pPDI is a perylene group monoimide functionalized in one of the coordinated phenanthroline ligands (Fig. 1). Our strategy is to keep the trischelate structure around the $\mathrm{Ru}(\mathrm{II})$ metal center using the complex

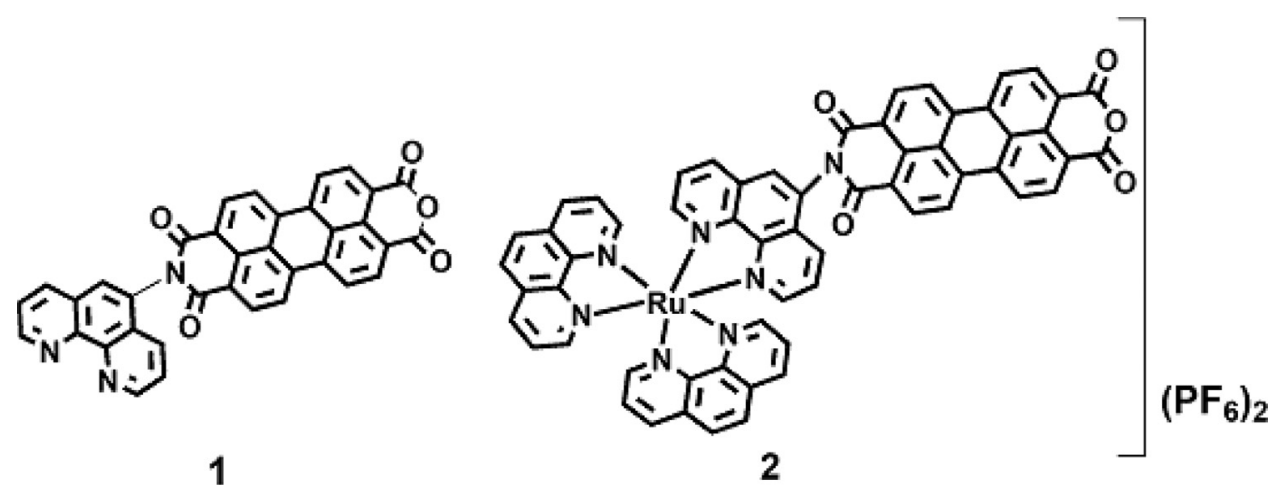

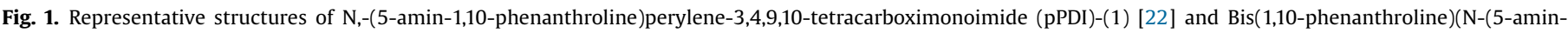

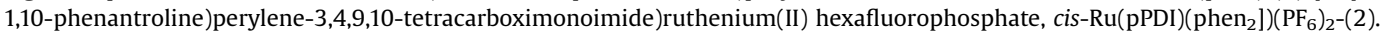


$\left[\mathrm{Ru}(\mathrm{phen})_{3}\right]^{2+}$ so as to improve the stability of the complex in question and to ensure strong absorption to the ${ }^{1 *}$ MLCT state. This state should rapidly decay to populate ${ }^{3 *}$ MLCT which may subsequently sensitize the formation of singlet oxygen. In addition, we expect that the compound solubility will increase after coordination to the metal ion.

One of the most important clinical pathogenic microorganisms is Candida albicans due to its remarkable virulence. C. albicans is recognized as the most common fungal pathogens, causing superficial infections of the skin and mucous membranes, reaching systemic levels, especially in immune-compromised individuals $[25,26]$. The resistance of $C$. albicans strains against classical antifungal agents such as fluconazole has increased considerably, which drives the search for new therapeutic alternatives [27-29]. In the present study, we report that our new Ru-perylene complex can indeed be used to kill the bacterium $C$. albicans.

\section{Experimental}

\subsection{Materials, spectroscopic measurements, and characterization}

Perylene-3,4,9,10-tetracarboxylic dianhydride, $\mathrm{RuCl}_{3} \times \mathrm{H}_{2} \mathrm{O}$, 1,10-phenanthroline (phen), zinc acetate, lithium chloride and tetrabutylammonium hexafluorophosphate were obtained from Aldrich. HPLC grade solvents were distilled just before being used in the spectroscopies experiments.

The complex cis-[Ru(phen $\left.)_{2}\left(\mathrm{H}_{2} \mathrm{O}\right)_{2}\right]\left(\mathrm{PF}_{6}\right)_{2}$ was prepared according to the procedures described in the literature [30,31]. The synthesis, electrochemical and spectroscopic experiments were conducted under nitrogen atmosphere.

The CHN elemental analysis of pPDI and cis-[Ru(phen $\left.)_{2}(\mathrm{pPDI})\right]$ $\left(\mathrm{PF}_{6}\right)_{2}$ complex was performed on an EA 1110 CHNS-O Carlo Erba Instrument. FTIR spectra were recorded on a Bomem-Michelson 102 spectrometer in solid state using CsI pellets in the range of $4000-300 \mathrm{~cm}^{-1}$.

The electronic absorption spectra were recorded on an Agilent 8453A UV-vis spectrophotometer or on a Jasco V-660 UV-vis spectrophotometer. Voltammetric measurements were carried out with a $\mu$ Autolab Type III potentiostat at $25^{\circ} \mathrm{C}$ without light. Glassy carbon electrode as working electrode $(\mathrm{d}=2 \mathrm{~mm})$, Pt electrode as counter electrode $(\mathrm{d}=4 \mathrm{~mm}), \mathrm{Ag} / \mathrm{AgCl}$ electrode as reference electrode, ferrocene as internal reference electrode and $\mathrm{TBAPF}_{6}$, $0.1 \mathrm{M}$, as supporting electrolyte. The scan rate was $100 \mathrm{mV} / \mathrm{s}$ and the concentration of the acetonitrile solutions that were used to perform cyclic voltammetry measurements of synthesized compounds was $10^{-3} \mathrm{~mol} \mathrm{~L}^{-1}$.

\subsubsection{Steady state spectroscopy}

The luminescence spectra were recorded on a Shimadzu RF5301PC spectrofluorometer or on a Horiba Jobin Yvon Fluorolog 322 spectrofluorometer. The concentration was $\sim 10^{-5} \mathrm{~mol} \mathrm{~L}^{-1}$ $\left(\lambda_{\text {absmaximum }}=0.3\right)$, solvent acetonitrile.

\subsubsection{Time-resolved photoluminescence}

The fluorescence intensity decay curves for the compounds with picosecond resolution were obtained using single photon timing technique with a DCM or Rhodamine dye laser (DCM $=4$ (Dicyanomethylene)-2-methyl-6-(4-dimethylaminostyryl)-4Hpyran). Intensity decay measurements were made by a collection of excitation and decay curves, using an emission polarizer set at the magic angle. The excitation profile was recorded at the excitation wavelength with a scattering suspension of the compound being investigated. For the decays, a cut-off filter was used to remove all excitation light. The emission signal passed through a depolarizer, a Jobin Yvon HR-320 monochromator with a grating of 100 lines/mm and was detected with a Hamamatsu
2809U-01 microchannel plate photomultiplier (MCP-PT). The instrument response had an effective FWHM of 35 ps. Fluorescence intensity decay curves were obtained by excitation light at $532 \mathrm{~nm}$ using the DCM and Rhodamine laser, with emission collected at $570 \mathrm{~nm}$, respectively. The decay curves were analyzed using homemade non-linear least-square deconvolution software based on the Levenberg-Marquardt algorithm, and the quality of the fit was evaluated by the reduced, the weight residuals and the autocorrelation of the residuals. The intensity of the fluorescence decay curves with nanosecond resolution was obtained on a Fluorolog Horiba Jobin Yvon. Program DataStation V 2.6-Horiba Jobin Yvon S1 Detector HV:950 V, Time Range: 400 ns, Peak Present: 65000 counts, Repetition Rate: $1 \mathrm{MHZ}$, Sync Delay: 50 ns. Fluorescence intensity decay curves were obtained by excitation light at $450 \mathrm{~nm}$ using DCM laser with emission collected at $600 \mathrm{~nm}$.

\subsubsection{Singlet oxygen detection}

The singlet oxygen experiments were performed at room temperature with a Nd-YAG nitrogen laser used for excitation (532 nm, ca. $600 \mathrm{ps}$ pulses, $\sim 1.6 \mathrm{~mJ} /$ pulse) with air-equilibrated samples [2]. The emission from singlet oxygen at $\lambda=1270 \mathrm{~nm}$ was detected at $90^{\circ}$ to the incident laser beam by a $5 \mathrm{MHz}$ germanium photodiode (Judson, J16-8SP-R05M-HS) working at room temperature. We employed several filters, namely a $1270 \mathrm{~nm}$ interference filter (Corion) or a combination of long-wave pass filters $(1000 \mathrm{~nm}$, $1100 \mathrm{~nm}, 1200 \mathrm{~nm}$, CVI Laser Corp.) to reduce scattered radiation from the laser (shortly after the laser pulse). The signal was amplified with a preamplifier (Oriel $70732,350 \mathrm{MHz}$ and Thorn EMI Electron Tubes A1 and/or A2). Decay curves were obtained with the help of an 8-bit AD-converter/recorder system (Fast TR50; $50 \mathrm{MHz}$ ), and each curve was the average of 60 decays. The optical densities at $532 \mathrm{~nm}$ were matched for the samples and methylene blue, which was used as the reference compound. The resultant emission curves were fitted with a single-exponential function to obtain the initial luminescence intensity at time $\mathrm{t}=0$ (or the intensity at any other time t) after the laser pulse. Experiments were done in methanol, acetonitrile, dichloromethane and acetone.

\subsubsection{Quantum yield of singlet oxygen}

Singlet oxygen quantum yield were determined by direct analysis of its near infrared luminescence intensity in different solvents. Measurements were made with two independent solutions, one containing the molecule under investigation and the other a reference $R$ ( $R=$ methylene blue), for which the quantum yield of singlet oxygen is known. The concentrations were adjusted so that the two solutions exhibited identical absorbance at the excitation wavelength [1]. Under these conditions, with identical laser pulse energy, the luminescence intensity ratio is related to the ratio of quantum yields of singlet oxygen production by the two sensitizers. The quantum yield of singlet oxygen was measured in dichloromethane, methanol, acetone, chloroform, and acetonitrile.

\subsection{Synthesis and characterization of pPDI and its Ru complex}

\subsubsection{Synthesis of the ligand phen-perylene (pPDI) N,-(5-amin-1,10-} phenanthroline)perylene-3,4,9,10-tetracarboximonoimide

A modified literature procedure [22] was used as follows: one equivalent $136 \mathrm{mg}(0.170 \mathrm{mmol})$ of perylene-3,4,9,10-tetracarboxylic-3,4,9,10-dianhydride (PTCDA) was dispersed in freshly distilled quinoline $(10 \mathrm{~mL})$ with one equivalent $32.30 \mathrm{mg}$ $(0.170 \mathrm{mmol})$ of 5 -amino-phenanthroline. Next $10 \%$ (by weight, relative to 5-amino-phenanthroline) anhydrous zinc acetate was added and the solution was heated under nitrogen to $220^{\circ} \mathrm{C}$ for $12 \mathrm{~h}$. After cooling, $15 \mathrm{~mL}$ of $1 \mathrm{M} \mathrm{HCl}$ was added and the precipitate 
was collected and rinsed with water and ether. We then added $150 \mathrm{~mL}$ of methanol, stirred for $30 \mathrm{~min}$ and allowed the mixture to stand for $4 \mathrm{~h}$ at $-10^{\circ} \mathrm{C}$, followed by washing with a $5 \%$ solution of sodium carbonate. After that, the compound was rinsed with methanol and dried under vacuum (50\% yield). Insufficient solubility for NMR; The synthesized pPDI (1) was characterized by MALDI-TOF mass spectra with parent molecular ion peaks appearing at $\left[m / z+3 \mathrm{H}^{+}\right]=570.2$ (Fig. S1- Supporting information), which is consistent with the theoretical value of exact mass. Anal. Calcd (found) for pPDI $\mathrm{C}_{36} \mathrm{H}_{15} \mathrm{~N}_{3} \mathrm{O}_{5}$ : C, 75.92 (76.36); $\mathrm{H}, 2.65$ (2.92); N, 7.38 (7.32)\%.

\subsubsection{Synthesis of bis(1,10-phenanthroline)(N-(5-amin-1,10-} phenantroline)perylene-3,4,9,10-tetracarboximonoimide)ruthenium

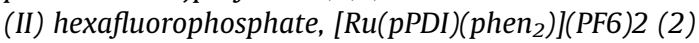

The cis-[Ru(phen)2(pPDI)](PF6)2 complex was synthesized by reacting cis-[Ru(1,10-phen $\left.)_{2}\left(\mathrm{H}_{2} \mathrm{O}\right)_{2}\right]\left(\mathrm{PF}_{6}\right)_{2}[11,30,31]$ with 1.2 eq. of pPDI in DMF. The complex was isolated as a hexafluorophosphate salt, whose composition and structure were verified by CHN analysis and mass spectrometry, respectively. (65\% yield). It was insufficiently soluble for characterization by NMR. The synthesized cis-[Ru(phen)2(pPDI) $]^{2+}$ complex was characterized by MS MALDITOF mass spectra with parent molecular ion peaks appearing at $\left[\left(\mathrm{M}-2 \mathrm{PF}_{6}\right)^{+2}=515.57\right]$, (Fig. S2- Supporting information), which is consistent with the theoretical value of the exact mass. Anal. Calcd (Found) for $\mathrm{C}_{60} \mathrm{H}_{31} \mathrm{~F}_{12} \mathrm{~N}_{7} \mathrm{O}_{5} \mathrm{P}_{2} \mathrm{Ru}$ : C, 69.23 (69.09); $\mathrm{H}, 2.66$ (2.61); $\mathrm{N}$, 10.09 (10.20)

\subsection{Biological experiments}

Initially, the lowest concentration dosage cytotoxic of photosensitizer cis-[Ru(phen $\left.)_{2}(\mathrm{pPDI})\right]^{2+}$ less cytotoxic was determined by a cytotoxicity test in mouse macrophages and subsequently, the highest concentration of photosensitizer with lower cytotoxicity was used to evaluate the antimicrobial capacity of the photosensitizer against $C$. albicans cells by photodynamic therapy. Cells culture and cytotoxicity tests were performed according to Oliveira et al. [32] with some modifications and the photodynamic therapy was performed according to Freire et al. [33] with modifications.

\subsubsection{Photosensitizer solutions}

Solutions of the photosensitizer were prepared by dissolving the powder in methanol and sterilized by filtration through a membrane with a pore size of $0.22 \mu \mathrm{m}$ (MFS, Dublin, CA, USA). After filtration, the photosensitizer solution was stored in the dark.

\subsubsection{Cell cultures}

Mouse macrophages (RAW 264.7) obtained from the Rio de Janeiro Cell Bank - Associação Técnico Científica Paul Ehrlich (APABCAM - Rio de Janeiro, RJ, Brazil) were cultured routinely in Dulbecco's Modified Eagle Medium (DMEM - LGC Biotechnology, Cotia, SP, Brazil) supplemented with $10 \%$ fetal bovine serum (FBS Gibco, USA) at $37^{\circ} \mathrm{C}$ in a $5 \% \mathrm{CO} 2$ atmosphere. Viable cells were counted by the Trypan blue $(0.5 \%$, Sigma-Aldrich, St. Louis, MO, USA) exclusion method.

\subsubsection{Cytotoxicity testing (MTT assay)}

For the experimental and positive control groups, $40 \times 10^{3}$ viable cells/well were seeded in 96-well plates (Nunc, Kamstrupvej, Roskilde, Denmark) and the plates were incubated for $24 \mathrm{~h}$ at $37^{\circ} \mathrm{C}$. Next, the cell cultures were exposed to $200 \mu \mathrm{L}$ of the serial dilutions of the photosensitizer $(100 \mu \mathrm{M}, 50 \mu \mathrm{M}, 25 \mu \mathrm{M}, 12.5 \mu \mathrm{M}$ and $6.5 \mu \mathrm{M}$ ) and incubated for $5 \mathrm{~min}$. At the end of the exposure, the cell culture medium was discarded and cell survival was determined by the MTT assay [MTT - (3-(4,5-dimethylthiazol-2yl))-2,5-diphenyltetrazolium bromide; Sigma-Aldrich].

The plates were washed with phosphate-buffered saline (PBS Cultilab, Campinas, São Paulo, Brazil) and $100 \mu \mathrm{L}$ MTT solution $(0.5 \mathrm{mg} / \mathrm{mL}$ in PBS) was added to each well. After incubation for $1 \mathrm{~h}$, MTT solution was removed and $100 \mu \mathrm{L}$ dimethyl sulfoxide (DMSO - Sigma-Aldrich) was added to each well. The plates were incubated for $10 \mathrm{~min}$ and then shaken on a shaker for an additional $10 \mathrm{~min}$. Optical densities were measured in a multi-well spectrophotometer (Bio-Tek, Winooski, Vermont, USA) at $570 \mathrm{~nm}$. The optical density values obtained for cultures exposed to the extracts were normalized to untreated control cultures (corresponding to $100 \%$ ). The results of the cytotoxicity tests were analyzed by ANOVA and the Tukey test $(\mathrm{P} \leq 0.05)$ using the BioEstat 5.0 software. The highest concentration of the photosensitizer which was less cytotoxic was selected for the subsequent test.

\subsubsection{Photodynamic therapy (PDT) assay on Candida albicans}

The $C$. albicans ATCC 18804 strain was seeded onto Sabouraud dextrose agar (Difco, Detroit, USA) and incubated at $37^{\circ} \mathrm{C}$ for $48 \mathrm{~h}$. After this period was prepared a standard suspension from the $C$. albicans colonies in physiological solution at a concentration of 106 cells/mL. The concentration was measured using a Neubauer chamber. For photodynamic inactivation, the standard suspension of the compound at a concentration of $12.5 \mathrm{mM}$ (concentration defined in the cytotoxicity test previously described) was tested for evaluating the yeast killing. The absorption spectrum of the cis-[Ru (phen $\left.)_{2}(\mathrm{pPDI})\right]^{2+}$ was determined by UV-vis spectroscopy. According to the experimental conditions, $0.1 \mathrm{~mL}$ of the $C$. albicans suspension was added to each well of a 96-well flat bottom microtiter plate (Costar Corning, New York, USA) with an area of $0.38 \mathrm{~cm}^{2}$. Next, the $\mathrm{P}+\mathrm{L}+$ and $\mathrm{P}+\mathrm{L}-$ groups $(\mathrm{P}=$ photosensitizer, $\mathrm{L}=$ light) received $0.1 \mathrm{~mL}$ of the cis- $\left[\mathrm{Ru}(\mathrm{phen})_{2}(\mathrm{pPDI})\right]^{2+}$ solution. For the $\mathrm{P}-\mathrm{L}+$ and $\mathrm{P}-\mathrm{L}-$ groups, $0.1 \mathrm{~mL}$ of physiological solution was added. For control methanol group $0,1 \mathrm{~mL}$ of methanol was added. The plates were shaken for 5 min (pre-irradiation time) in an orbital shaker (Solab, Piracicaba, Brazil). Next, each well of the groups submitted to the $c i s-\left[\mathrm{Ru}(\mathrm{phen})_{2}(\mathrm{pPDI})\right]^{2+}$ and LED and the $\mathrm{P}-\mathrm{L}+$ group were irradiated separately. A green LED (MMOptics, São Carlos, Brazil) with a wavelength of $532 \pm 10 \mathrm{~nm}$, output power of $90 \mathrm{~mW}$, fluency of $42.63 \mathrm{~J} \mathrm{~cm}^{2}$ (energy of $16.2 \mathrm{~J}$ and area of 0.38 ), time of $180 \mathrm{~s}$, and fluency rate of $237 \mathrm{~mW} \mathrm{~cm}^{2}$ was used for irradiation. The irradiation was performed under aseptic conditions in a laminar flow hood protected from light. A matte black screen with a hole whose diameter corresponded to the size of the well entrance was used to prevent the scattering of light. After irradiation, serial dilutions were prepared and $0.1-\mathrm{mL}$ aliquots were spread on Sabouraud dextrose agar plates in duplicate. The plates were incubated at $37^{\circ} \mathrm{C}$ for $48 \mathrm{~h}$. After incubation, the number of colonies forming units per milliliter $(\mathrm{CFU} / \mathrm{mL})$ was determined and the results were log transformed.

\subsection{Computational methods}

All calculations were performed with the Gaussian 09 (G09) program package $[34,35]$, edition D.01, employing the DFT method with Becke's three-parameter hybrid functionaly and Lee-YangParr's gradient corrected correlation functional [35-37] (B3LYP) in combination with LanL2DZ basis set [37]. The ground-state geometries of the complexes were optimized in the gas phase. SCF-tight convergence criteria were used for all optimizations. The solvent DMSO was included in the calculations using the PCM system. The triplet state was obtained using UB3LYP/LANL2DZ. Electronic analysis was performed using TD-DFT calculations with 40 excited states. 


\section{Results and discussion}

\subsection{Synthesis and characterization}

\subsubsection{Structural and optical characterization}

Our attempts to grow diffraction-quality crystals of the synthesized free ligand (pPDI) and of the Ru complex were not successful. We therefore determined the structural parameters and electronic effects on the coordination of the pPDI to the cis-[Ru $(\mathrm{phen})_{2}$ ] with DFT calculations. Fig. 2 shows the optimized structure for pPDI and cis-[Ru(phen $\left.)_{2}(\mathrm{pPDI})\right]^{2+}$. The vibrational modes were obtained ensuring that imaginary frequencies were not generated in the minimum structures. The good agreement between the absorption and infrared theoretical and experimental data are discussed below.

The optimized structure of the substituted perylene ligand shows that the perylene moiety is perpendicular to the phenanthroline ligand, and the predicted dihedral angle between the phenanthroline and the perylene is $89.8^{\circ}$. After coordination of the pPDI ligand to the $\mathrm{Ru}(\mathrm{II})$ moiety, no pronounced changes are observed in the bond lengths and angles of the pPDI ligand. The most noticeable difference is the slight decrease in the perpendicularity of the phen-perylene ligand, as the dihedral angle in the complex is $85.6^{\circ}$. These changes do not affect the orbital composition indicating that the emissive properties of the pPDI will be not affected by the coordination to the metal complex.

\subsubsection{IR spectra}

The experimental IR spectra for the free pPDI and for the complex cis-[Ru(phen)2(pPDI)](PF6)2 (Fig. S3-Supporting information) exhibit stretching bands consistent with the proposed structures [38]. For the pPDI the absorption band at $1766 \mathrm{~cm}^{-1}$ refers to the carbonyl anhydride stretch and the bands at 1703 and $1666 \mathrm{~cm}^{-1}$ correspond to the stretches of the imide group $\nu \mathrm{C}-\mathrm{O}$ $[11,12,22,38]$.

The band at $1029 \mathrm{~cm}^{-1}$ refers to $\nu \mathrm{C}-\mathrm{O}-\mathrm{C}$ of the anhydride and at $1358 \mathrm{~cm}^{-1}$ corresponds to the $\mathrm{C}-\mathrm{N}$ amine formed by the replacement of the oxygen atom of the anhydride by the nitrogen of phenanthroline, showing that phenanthroline was functionalized in only one Perylene side [39]. For the $\left[\mathrm{Ru}(\mathrm{phen})_{2}(\mathrm{pPDI})\right]\left(\mathrm{PF}_{6}\right)_{2}$ complex the bands are shown at 1705,1659 and $1359 \mathrm{~cm}^{-1}$ attributed to the stretches of the imide and imine groups ( $\nu_{\mathrm{CO}}$ and $\nu_{\mathrm{CN}}$ ), respectively [39]. The bands observed at 860 and $557 \mathrm{~cm}^{-1}$, are assigned to the $\mathrm{P}-\mathrm{F}$ stretch from the $\mathrm{PF}_{6}{ }^{-},[11]$. In the theoretical spectrum for both the pPDI and Ru complex (Figs. S4 and S5 Supporting information), the vibrational modes of the imine and imide groups are found at 1707, 1633, 1606 and $1339 \mathrm{~cm}^{-1}$. The presence of a more intense band at $1339 \mathrm{~cm}^{-1}$ and also the appearance of the Ru-N stretching at $400-700 \mathrm{~cm}^{-1}$ in the measured spectrum are present after the coordination of the pPDI to the Ru-complex.

\subsubsection{Cyclic voltametry}

The electrochemical behavior of the complex cis-[Ru(phen)2 $(\mathrm{pPDI})]^{2+}$ was investigated by cyclic voltammetry in order to evaluate the effect of the metal coordination on the reductive and oxidative potentials. The cyclic voltammogram of the complex in $\mathrm{CH}_{3} \mathrm{CN}$ solution using a Pt electrode at the scanning rate of $100 \mathrm{mV} \mathrm{s}^{-1}$ is shown in Fig. 3. Using the data from the voltammetric curves, we identified the redox pairs at $-0.25 /$ $0.04 \mathrm{~V},\left(\mathrm{E}^{1} / 2=-0.15 \mathrm{~V}\right)$ and $-0.65 /-0.39 \mathrm{~V}\left(\mathrm{E}^{1} / 2=-0.52 \mathrm{~V}\right)$ vs $\mathrm{Ag}$ $+/ \mathrm{AgCl}$, which were assigned to the anionic (pPDI/pPDI ${ }^{--}$) and dianion radicals $\left(\mathrm{pPDI}^{\bullet-} / \mathrm{pPDI}^{-2}\right.$ ) moieties of the cis-[Ru(phen)2 $(\mathrm{pPDI})]^{2+}$ respectively, as reported for other perylene derivatives $[20,22,40,41]$. The electrochemical reductive process at $-1.07 \mathrm{~V}$ and $-1.22 /-1.07 \mathrm{~V}\left(\mathrm{E}^{1} / 2=-1.15 \mathrm{~V}\right)$ were assigned to the phenanthroline ligand coordinated to the metal center $\mathrm{Ru}(\mathrm{II})$.

At $100 \mathrm{mV} \mathrm{s}^{-1}$, the irreversible oxidative process at $1.17 \mathrm{~V} v \mathrm{sg}$ $+/ \mathrm{AgCl}$ was assigned to species $\mathrm{Ru}(\mathrm{II}) \rightarrow \mathrm{Ru}(\mathrm{III})[11,38,41]$. This oxidation potential is much higher than that observed for the precursor cis- $\mathrm{RuCl}_{2}(1,10 \text {-phen })_{2},+0.43 /+0.35 \mathrm{~V}(\Delta \mathrm{E}=60 \mathrm{mV})$, probably because of the electron withdrawing character of the perylene group, which makes the metal center more electron-deficient.

\subsubsection{Ground state absorption and luminescence}

Since the free pPDI showed low solubility in $\mathrm{CH}_{3} \mathrm{CN}$, the absorption spectrum was obtained using diluted DMSO solutions $\left(1.1 \times 10^{-6} \mathrm{~mol} \mathrm{l}^{-1}\right)$, as seen in Fig. 4 .

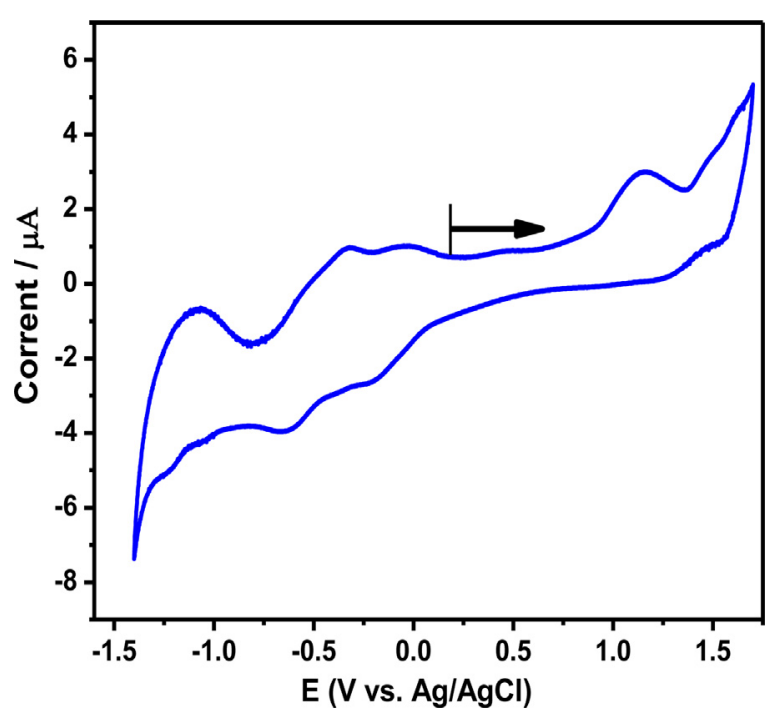

Fig. 3. Cyclic voltammogram of cis- $\left[\mathrm{Ru}(\mathrm{phen})_{2}(\mathrm{pPDI})\right]^{2+}$ complex in acetonitrile $(0.1 \mathrm{M})(\mathrm{nBu})_{4} \mathrm{NPF}_{6}$, platinum working electrode, (potential versus $\mathrm{Ag} / \mathrm{AgCl}$ ) and scan rate of $100 \mathrm{mV} \mathrm{s}^{-1} . \mathrm{E}_{1 / 2}$ for $\mathrm{Fc}^{+} / \mathrm{Fc}$ couple $=+0.54 \mathrm{~V}$ measured under the same experimental conditions.
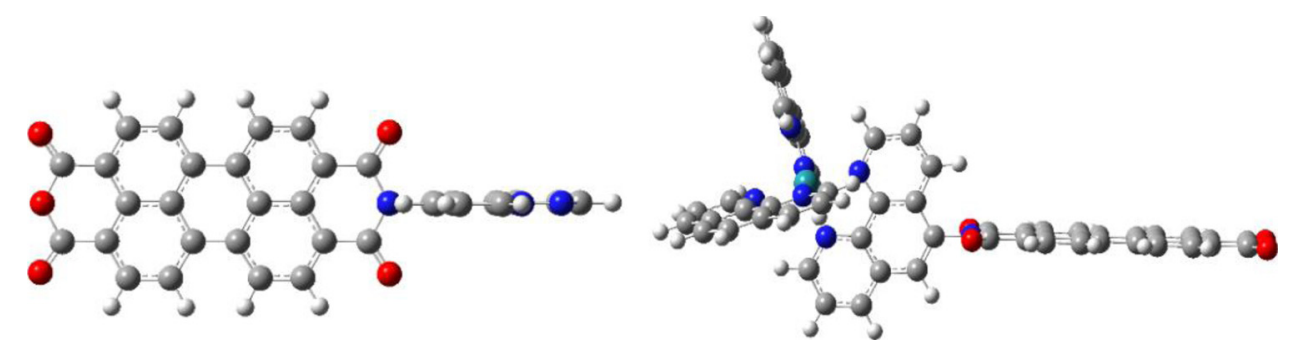

Fig. 2. DFT optimized structure of ligand pPDI $[22]$ and $c i s-\left[R u(p h e n)_{2}(p P D I)\right]^{2+}$. 


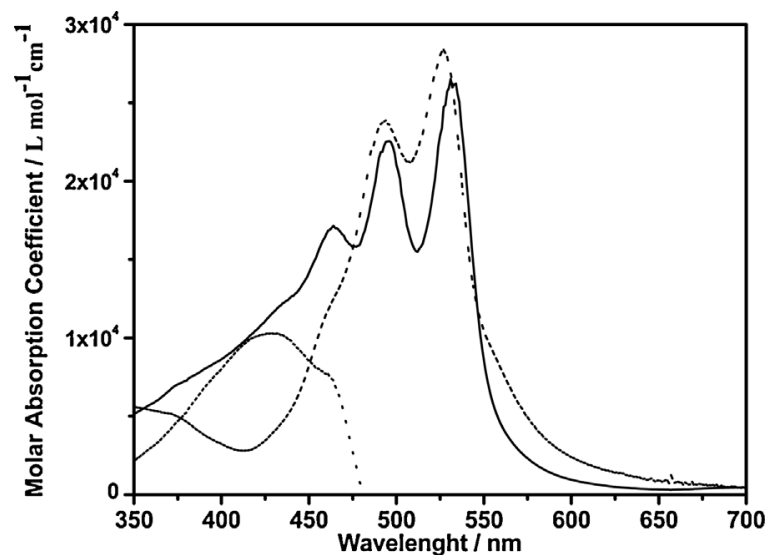

Fig. 4. UV-vis absorption spectrum (solid) of a $5.0 \times 10^{-6} \mathrm{~mol} \mathrm{~L}^{-1}$ solution of cis$\left.[\mathrm{Ru} \text { (phen })_{2}(\mathrm{pPDI})\right]\left(\mathrm{PF}_{6}\right)_{2}$ in DMSO and the contributions of the free pPDI also in DMSO (short dash) and $\left\{\mathrm{Ru}(\mathrm{phen})_{3}\right\}^{2+}$ MLCT absorption (dot) bands.

The UV-vis spectrum of pPDI exhibits a broad band with a shoulder at $555 \mathrm{~nm}$ and three distinct maxima at $533 \mathrm{~nm}, 493 \mathrm{~nm}$, and $462 \mathrm{~nm}$ attributed to the $\pi-\pi^{*}$ electronic transitions of the perylene [11,22,39-41]. The electronic spectrum of the complex cis- $\left[\mathrm{Ru}(\mathrm{phen})_{2}(\mathrm{pPDI})\right]^{2+}$ as seen in Fig. 3 exhibits transitions characteristic of the free pPDI along with the broad absorption band assigned as a MLCT of the complex $[\operatorname{Ru}(\text { phen }) 3]^{2+}$, with the maximum absorption at $\sim 450 \mathrm{~nm}$.

The theoretical electronic spectrum of the pPDI ligand shows a band at $\lambda_{\max }=555 \mathrm{~nm}$ assigned to $\pi_{\text {pery }} \rightarrow \pi^{*}$ pery transition (100\% HOMO $\rightarrow$ LUMO) located completely on the perylene ring [22]. For the complex cis-[Ru(phen $\left.)_{2}(\mathrm{pPDI})\right]^{2+}$ the theoretical electronic spectrum (Fig. S6- Supporting information) has a band at $556 \mathrm{~nm}$ due to the $\pi_{\text {pery }} \rightarrow \pi^{*}$ pery transition of the perylene ligand (100\% HOMO-3 $\rightarrow$ LUMO) and the transition at $447 \mathrm{~nm}$ caused by MLCT $\mathrm{d}_{\mathrm{Ru}} \rightarrow \pi^{*}$ phen $(43 \%$ HOMO-2 $\rightarrow$ LUMO +1 ), as shown in Fig. 5 .

The absorption bands of the cis-[Ru(phen $\left.)_{2}(\mathrm{pPDI})\right]^{2+}$ did not change significantly relative to those of free pPDI. This observation is related to the fact that the pPDI moiety and the Ru metal center are in different nodal plans, a characteristic that has also been observed in other polypyridine complexes of $\mathrm{Ru}$ with aromatic chromophores [11,39,42]. This indicates that the complex does not behave as a conjugated super-molecule, but rather as an electron receptor-donor dyad.

The shape of the fluorescence spectra of $c i s-\left[\mathrm{Ru}(\mathrm{phen})_{2}(\mathrm{pPDI})\right]^{2}$ ${ }^{+}$is characteristic of the free perylene emission [10,11,13,16,22,43]. To study the effect of the perylene chromophore on polypyridine complexes, the compounds were excited at three different wavelengths ( $413 \mathrm{~nm}, 460 \mathrm{~nm}$ and $495 \mathrm{~nm}$ ). Upon excitation at $413 \mathrm{~nm}$, the complex exhibits a broad emission band (Fig. 6A). When excited at the $460 \mathrm{~nm}$ and $495 \mathrm{~nm}$ lengths (Fig. 6B and C, respectively), we observed that the complex exhibits a broadband with maximum at $550 \mathrm{~nm}$ and three distinct peaks, assigned the ILCT transitions of the perylene group with $\lambda_{\max }$ at 550, 584, and $635 \mathrm{~nm}$, related to $(0 \leftarrow 0),(0 \leftarrow 1)$ and $(0 \leftarrow 2)$, respectively, suggesting a different distribution of the excitation light between the molecules $\{\mathrm{Ru}(\mathrm{phen}) 3\}^{2+}$ and the free pPDI at each excitation length.

In agreement with these results, the excitation spectra obtained at $460 \mathrm{~nm}$ and $600 \mathrm{~nm}$ show two overlapping absorption bands characteristic of the $\{$ pPDI $\}$ and $\left\{\mathrm{Ru}(\mathrm{phen})_{3}\right\}^{2+}$ moieties.

The approximate mirror-image relation between the absorption and fluorescence bands at $460 \mathrm{~nm}$ and $490 \mathrm{~nm}$ are caused by relatively small differences between the geometry of the ground $S_{0}$ and excited singlet state $S_{1}$, which are typical for the rigidity and planarity of the polycyclic aromatic molecules [17,22,42].

These results were confirmed by the time-resolved luminescence decays of air equilibrated dilute solutions of the complex cis$\left.[\mathrm{Ru} \text { (phen })_{2}(\mathrm{pPDI})\right]^{2+}$ in $\mathrm{CH}_{3} \mathrm{CN}$ and the free $\mathrm{pPDI}$ in DMSO solutions (Figs. S7 and S8 - Supporting information). When excited in the absorption region of the MLCT transition $(445 \mathrm{~nm})$, both the $\{\mathrm{Ru}$ $\left.(\mathrm{phen})_{2}\right\}^{2+}$ and the $\{\mathrm{pPDI}\}$ moieties are electronically excited. The complex cis-[Ru(phen $\left.)_{2}(\mathrm{pPDI})\right]^{2+}$ showed a bi-exponential behavior with lifetimes of $5.06 \mathrm{~ns}(48.1 \%)$ and $156 \mathrm{~ns}$ (51.9\%), resulting from pPDI and ${ }^{3}$ MLCT emission, respectively. By excitation at $532 \mathrm{~nm}$, the cis- $\left[\mathrm{Ru}(\mathrm{phen})_{2}(\mathrm{pPDI})\right]^{2+}$ showed a bi-exponential behavior with lifetime of $0.60 \mathrm{~ns}(1.27 \%)$ and $4.25 \mathrm{~ns}(98.73 \%)$ caused by pPDI emission, consistent with the lifetime of $4.83 \mathrm{~ns}$ observed for the free ligand.

The emission from the free pPDI exhibited a bi-exponential behavior when $\lambda_{\text {exc }}=515 \mathrm{~nm}$ with $\lambda_{\text {em }}=550 \mathrm{~nm}$. Kirmaie and coworkers [44] suggested that a lifetime on the order of $1 \mathrm{~ns}$ in the perylene dye emission is related to the fluorescence via molecular vibrations. The longer lifetime (on the order of $5 \mathrm{~ns}$ ) is attributed to the transition $S_{0} \leftarrow S_{1}[41,42]$. After coordination to the metal ion, the emission with the shortest lifetime can no longer be detected.

Excitation in the visible region will ultimately lead to intersystem crossing and population of the lowest energy ${ }^{3} \mathrm{MLCT}$ state. Indeed, the orbital composition for the lowest triplet state optimized structure shows that the HOMO is mainly composed of perylene and the LUMO by Ru-phen moiety. The spin density distribution for the triplet optimized structure is completely located on the perylene ligand, Fig. 7.

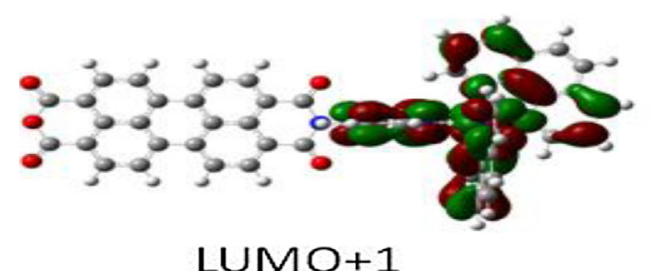

LUMO+1

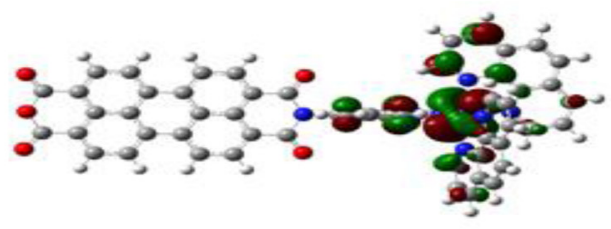

HOMO-2

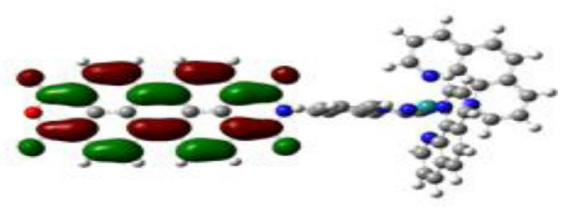

LUMO

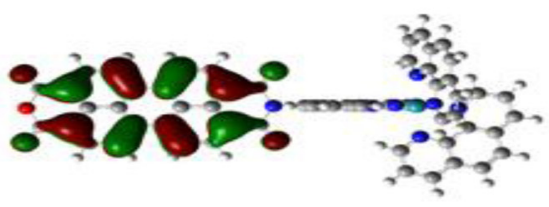

HOMO-3

Fig. 5. Contour surfaces for the HOMOs and LUMOs orbitals of the cis-[Ru(phen $\left.)_{2}(\mathrm{pPDI})\right]^{2+}$. 

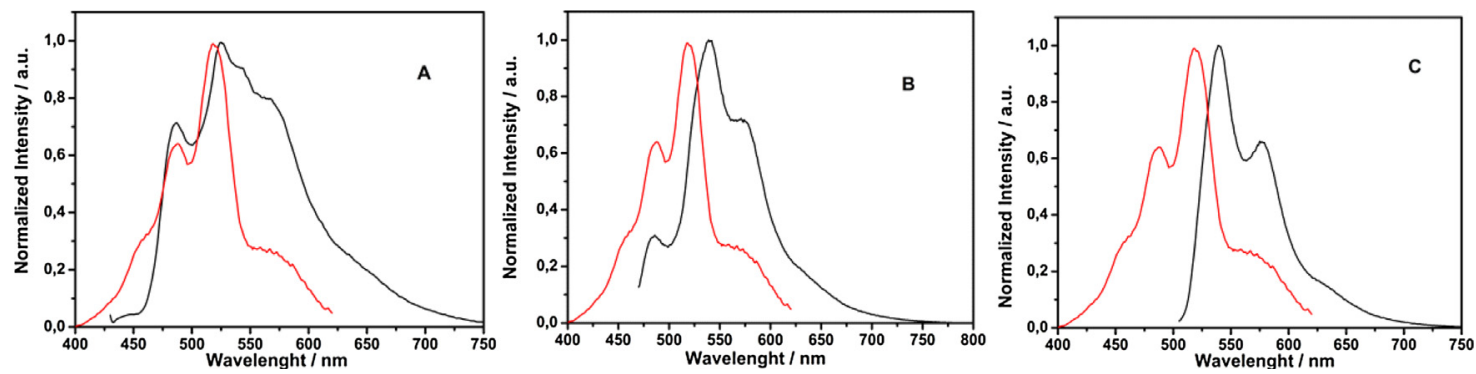

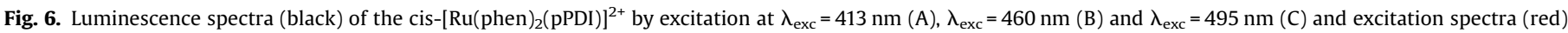
recorded at $\lambda_{\mathrm{em}}=620 \mathrm{~nm}$ in DMSO. (For interpretation of the references to colour in this figure legend, the reader is referred to the web version of this article.)

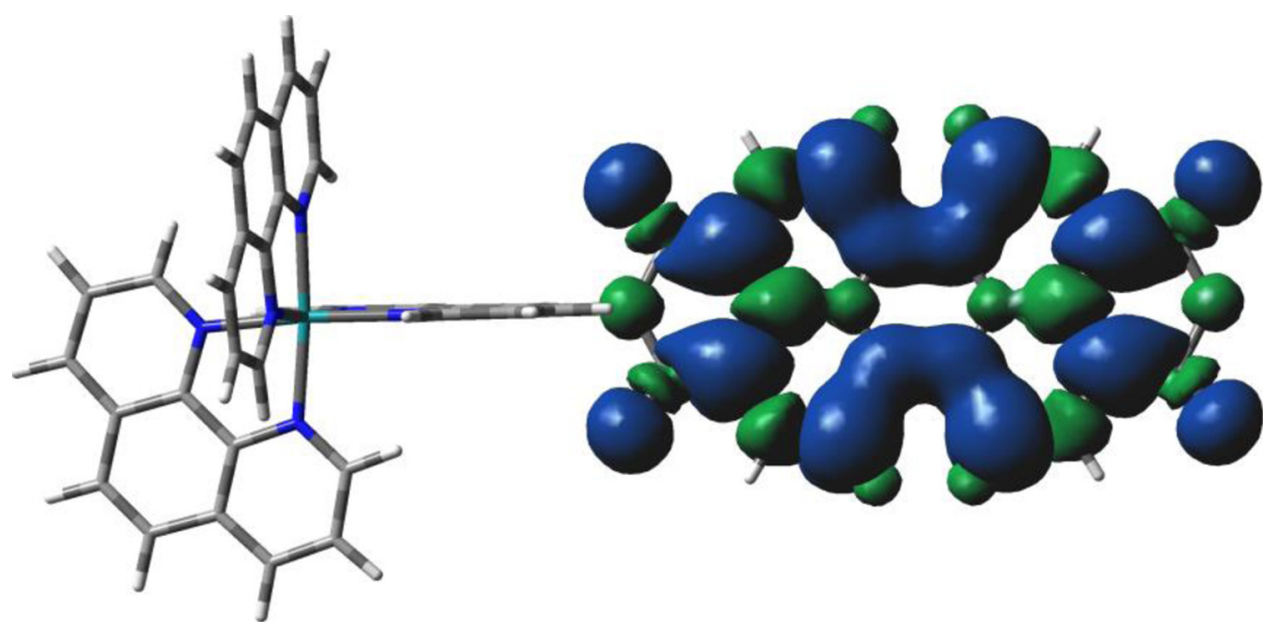

Fig. 7. Spin density distribution in the geometry optimized ${ }^{3}$ MLCT of compound cis- $\left[\mathrm{Ru}(\mathrm{phen})_{2}(\mathrm{pPDI})\right]^{2+}$

TD-DFT vertical excitation revealed that the $\mathrm{T}_{2}$ and $\mathrm{S}_{1}$ levels of the compound cis-[Ru(phen $\left.)_{2}(\mathrm{pPDI})\right]^{2+}$ are degenerate $(1.88 \mathrm{eV})$ and very close in energy to the $\mathrm{T}_{3}$ and $\mathrm{S}_{2}(2.0 \mathrm{eV})$ levels which are degenerate as well. $\mathrm{T}_{2}$ and $\mathrm{S}_{1}$ are characterized by $\mathrm{Ru} \rightarrow \pi^{*}$ pery charge transfer and $T_{3}$ and $S_{2}$ by the $\pi_{\text {pery }} \rightarrow \pi^{*}$ pery transition.

\subsection{Singlet oxygen measurements - efficiency of singlet oxygen photogeneration}

Although PDIs are known as dyes with high fluorescence quantum yields, a number of transition-metal complexes of PDI dyes were recently reported to accelerate intersystem crossing (ISC) from singlet to triplet-excited state. As a consequence, under aerobic conditions, formation of ${ }^{1} \mathrm{O}_{2}$ is possible $[14,40,43,44]$. Therefore, we investigated formation of ${ }^{1} \mathrm{O}_{2}$ from our compounds upon light irradiation. ${ }^{1} \mathrm{O}_{2}$ quantum yields were evaluated for the complex by using the direct observation of the near infrared (NIR) singlet oxygen emission signal.

The quantum yield of singlet oxygen production by cis-[Ru (phen $\left.)_{2}(\mathrm{pPDI})\right]^{2+}$ was measured in dichloromethane, chloroform, and acetonitrile. Methylene blue was used as the reference sensitizer. The free ligand pPDI did not show any singlet oxygen production. On the other hand, the complex cis-[Ru(phen $\left.)_{2}(\mathrm{pPDI})\right]^{2}$ + does generate singlet oxygen with moderate efficiency; the quantum yields of singlet oxygen generation in different solvents are given in Table 1. All measurements were made in triplicates. It is striking that the quantum yields do not vary much across solvents with different dielectric constants. This indicates that
Table 1

Quantum yields of singlet oxygen measured upon irradiation at $532 \mathrm{~nm}$ for complex 1 in different deuterated organic solvents.

\begin{tabular}{lll}
\hline Solvent & $\Phi \Delta$ cis-[Ru(phen $\left.)_{2}(\mathrm{pPDI})\right]^{2+}$ & $\Phi_{\Delta}$ Methylene Blue \\
\hline c,d dichloromethane & $0.24 \pm 0.005$ & 0.57 \\
${ }^{\mathrm{c}, \mathrm{d}}$ methanol-d4 & $0.23 \pm 0.06$ & $0.58^{6,7}$ \\
${ }^{\mathrm{a}, \mathrm{b}}$ acetonitrile-d3 & $0.26 \pm 0.005$ & $0.57^{7,10,13}$ \\
c,d acetonitrile & $0.24 \pm 0.002$ & 0.52 \\
${ }^{\mathrm{a}, \mathrm{d}}$ chloroform & $0.18 \pm 0.006$ & $0.52,{ }^{10,13}$ \\
\hline
\end{tabular}

The measurements were made in triplicates. Error is given as one standard deviation.

a Saturated atmosphere $\mathrm{O}_{2}$.

b Deuterated solvent.

c Air saturated atmosphere.

d Anhydrous solvent.

singlet oxygen generation via charge-transfer intermediates is probably not a significant pathway for this complex.

The ability to produce singlet oxygen depends largely on the production of a long-lived triplet state, [13,14,17,18] and the moderate quantum yield values of ${ }^{1} \mathrm{O}_{2}$ and the high absorbance of the perylene moiety in the visible range make cis-[Ru (phen $\left.)_{2}(\mathrm{pPDI})\right]^{2+}$ a possible photosensitizer to be used in water disinfection or other singlet oxygen-base processes that use sunlight as an excitation source. Since the Ru complex has a long-lived triplet state, it is of possible that in addition to formation of singlet oxygen, formation of superoxide anion by electrontransfer processes and/or Type I photooxidation processes take place upon irradiation of the Ru complex under aerobic conditions. The reactive oxygen species resulting from these processes may 
also be involved in the fungicidal processes described in Sections 3.3 and 3.4 below.

\subsection{Cytotoxicity assays of the PSs in mouse macrophages}

The cytotoxicity tests were performed in order to obtain the concentration of the cis-[Ru(phen $\left.)_{2}(\mathrm{pPDI})\right]^{2+}$ complex (without irradiation) that has low cytotoxicity, as we are interested in observing the toxicity from singlet oxygen.

The photosensitizer showed high cytotoxicity at concentrations above $25 \mu \mathrm{M}$. The concentrations of $12.5 \mu \mathrm{M}$ and $6.25 \mu \mathrm{M}$ were the concentrations that presented low cytotoxicity represented by high cell viability (Fig. 8). For the subsequent test the concentration of $12.5 \mu \mathrm{M}$ was selected, since this concentration showed low cytotoxicity in comparison to the higher concentrations.

\subsection{Photodynamic inactivation assays for Candida albicans}

After observing the light-dependent ${ }^{1} \mathrm{O}_{2}$ production by complex cis-[Ru(phen $\left.)_{2}(\mathrm{pPDI})\right]^{2+}$, and their effect on mouse macrophages cultures, these systems were tested as active components in antimicrobial photodynamic therapy. Owing to its medical importance, $C$. albicans was chosen as the model microorganism. The viability of these cells as a function of different exposure, and different conditions during the experiments is shown in Fig. 9.

For the photodynamic therapy (PDT) test, we used the concentration of the photosensitizer of $12.5 \mu \mathrm{M}$, as that was the concentration that presented low cytotoxicity represented by high macrophages cells viability in previous test described (Cytotoxicity Assay).

We observed that the group that was exposed only to the photosensitizer (no irradtion, $\mathrm{P}+\mathrm{L}-$ ) presented a statistically significant reduction of $C$. albicans when compared to the P-Land $\mathrm{P}-\mathrm{L}+$ control groups $(\mathrm{p}=0.0053$ and $\mathrm{p}=0.0030$ ). There was no statistical difference when these groups (P-L- and P-L+) was compared to the methanol group $(\mathrm{p}=0.1764)$, indicating that the photosensitizer, independent of the methanol activity, had fungicidal action on $C$. albicans cells. Regarding the PDT group $(\mathrm{P}+\mathrm{L}+)$, we observed that this group showed by far the most inhibitory action on $C$. albicans in comparison with all the other experimental groups $(\mathrm{p}<0.0001)$.

Freire et al. in 2013 [33] studied the ability of Rose Bengal (RB) and Eosin Y (2,4,5,7 tetrabromofluorescein) for photoinactivation in C. albicans. These authors used the C. albicans biofilm formation

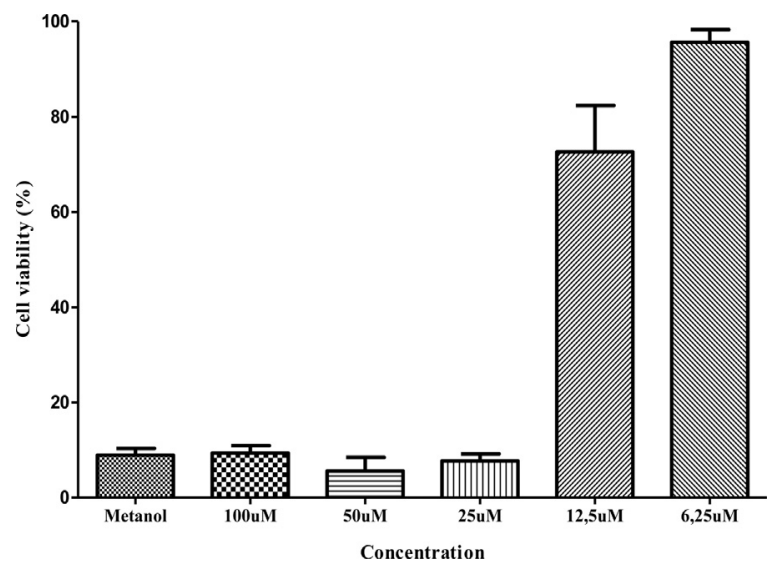

Fig. 8. Percentage average and standard deviation of cell viability of macrophages RAW 265.7 exposed to different concentrations of the photosensitizer cis-[Ru $\left.(\text { phen })_{2}(\mathrm{pPDI})\right]^{2+}$

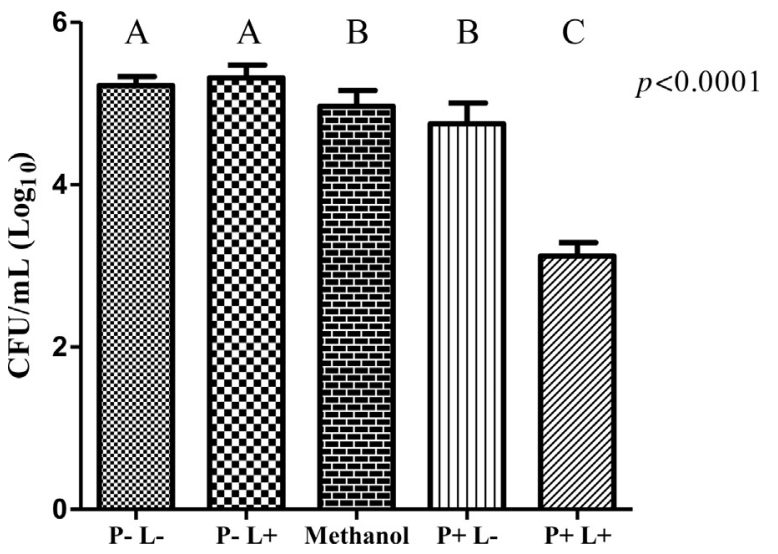

Fig. 9. Colony-forming units $(\mathrm{CFU} / \mathrm{mL})$ of $C$. albicans average and standard deviation after different treatments with the photosensitizer cis- $\left[\mathrm{Ru}(\mathrm{phen})_{2}(\mathrm{pPDI})\right]^{2+}$. Experimental groups: $\mathrm{P}+\mathrm{L}+$ photosensitizer and light irradiation, $\mathrm{P}+\mathrm{L}-$ only treated with the photosensitizer, $\mathrm{P}-\mathrm{L}+$ only light irradiation, $\mathrm{P}-\mathrm{L}-$ control group not submitted to the photosensitizer or light irradiation, methanol is the control group of this solvent.

for evaluation. After treatment with RB $200 \mu \mathrm{M}$ or Eosin $\mathrm{Y}$, inactivation rates of 0.22 and $0.45 \log _{10}$ were observed for RB and Eosin Y, respectively. In our study, the PDT $(\mathrm{P}+\mathrm{L}+)$ with the compound and light showed significant log reduction $\left(2.09 \log _{10}\right)$ expressed in $\mathrm{CFU} / \mathrm{ml}$ of $C$. albicans, as described above. The organization in biofilm allows a greater resistance of the microorganisms against antimicrobial agents than the planktonic cells organization. In our study, we have established that a there is a significant antimicrobial effect of cis-[Ru(phen $\left.)_{2}(\mathrm{pPDI})\right]^{2}$ and a considerable rate of microbial reduction at low concentrations of the photosensitizer. For example, we obtained reduction of 2.09 $\log _{10}$ at a concentration of $12.5 \mu \mathrm{M}$ of this photosensitizer, while Peloi et al., 2008 [45] using a methylene blue concentration of $35.2 \mu \mathrm{M}$ observed a reduction of 2.77-3.87 $\log _{10}$.

\section{Conclusion}

We have successfully prepared and characterized new perylene derivatives and a cis- $\left[\mathrm{Ru}(\mathrm{phen})_{2}(\mathrm{pPDI})\right]^{2+}$ complex in which a perylene moiety has been attached to one of the ligands. "The optimized structure of the new substituted perylene ligand shows that the perylene moiety is perpendicular to the phenanthroline ligand. After coordination of the pPDI ligand to the Ru(II) moiety, no pronounced changes are observed in the bond lengths and angles of the pPDI ligand. The coordination does not affect the orbital make-up, indicating that the emissive properties of the pPDI are not affected by the coordination to the metal complex. In addition, the absorption bands and the shape of the fluorescence spectra of the cis-[Ru(phen $\left.)_{2}(\mathrm{pPDI})\right]^{2+}$ did not change significantly relative to those of free pPDI. These observation is consistent with the pPDI moiety and the Ru metal center being in different nodal plans."

Upon irradiation in the visible range, the latter Ru complex does produce singlet oxygen. The photosensitizer diluted in methanol to a concentration of $12.5 \mu \mathrm{M}$ presents lower cytotoxicity compared to the others concentrations of this compound and, this photosensitizer can statistically inhibit $C$. albicans cells. Despite the modest singlet oxygen quantum yield, the high molar absorptivity of the perylene ligand makes our system a possible agent for photodynamic therapy against $C$. albicans. Our results demonstrate the potential use of such Ru metal complexes for fungicidal photodynamic therapy against $C$. albicans. 


\section{Acknowledgements}

The authors would like to acknowledge FAPESP, (process $n^{\circ}$. 2012/09449-8 and 2014/17476-0), CNPq, and CAPES for the grants and fellowships received. The authors are indebted to D.Z. and M.S. gratefully acknowledges support from the NSF-CREST program (NSF-HRD 1547723).

\section{Appendix A. Supplementary data}

Supplementary data associated with this article can be found, in the online version, at https://doi.org/10.1016/j.jphotochem.2017.12.020.

\section{References}

[1] C. Schweitzer, R. Schmidt, Physical mechanisms of generation and deactivation of singlet oxygen, Chem. Rev. 103 (2003) 1685-1758, doi:http://dx.doi.org/ 10.1021/cr010371d.

[2] D. Ashen-Garry, M. Selke, Singlet oxygen generation by cyclometalated complexes and applications, Photochem. Photobiol. 90 (2014) 257-274, doi: http://dx.doi.org/10.1111/php.12211.

[3] F. Doria, I. Manet, V. Grande, S. Monti, M. Freccero, Water-soluble naphthalene diimides as singlet oxygen sensitizers, J. Org. Chem. 78 (2013) 8065-8073, doi: http://dx.doi.org/10.1021/jo401347z.

[4] V. Prusakova, C.E. McCusker, F.N. Castellano, Ligand-localized triplet-state photophysics in a platinum(II) terpyridyl perylenediimideacetylide, Inorg. Chem. 51 (2012) 8589-8598, doi:http://dx.doi.org/10.1021/ic301169t.

[5] B. Bruner, M.B. Walker, M.M. Ghimire, D. Zhang, M. Selke, K.K. Klausmeyer, M. A. Omary, P.J. Farmer, Ligand-based photooxidations of dithiomaltolato complexes of $\mathrm{Ru}(\mathrm{II})$ and $\mathrm{Zn}(\mathrm{II})$ : photolytic $\mathrm{CH}$ activation and evidence of singlet oxygen generation and quenching, Dalton Trans. 43 (2014) 11548-11556, doi: http://dx.doi.org/10.1039/c4dt00961d.

[6] A.A. Abdel-Shafi, H.A. Hassanin, S.S. Al-Shihry, Partial charge transfer contribution to the solvent isotope effect and photosensitized generation of singlet oxygen, $\mathrm{O} 2 \Delta 1(\mathrm{~g})$, by substituted ruthenium(II) bipyridyl complexes in aqueous media, Photochem. Photobiol. Sci. 13 (2014) 1330-1337, doi:http://dx. doi.org/10.1039/c4pp00117f.

[7] A.A. Abdel-Shafi, D.R. Worrall, A.Y. Ershov, Photosensitized generation of singlet oxygen from ruthenium(ii) and osmium(ii) bipyridyl complexes, Dalt. Trans. 103 (2004) 30-36, doi:http://dx.doi.org/10.1039/b310238f.

[8] J.N. Demas, E.W. Harris, R.P. McBride, Energy transfer from luminescent transition metal complexes to oxygen, J. Am. Chem. Soc. 99 (1977) 3547-3551, doi:http://dx.doi.org/10.1021/ja00453a001.

[9] T.Q. Ni, L.A. Melton, Non-radiative PII-, 67 (1992).

[10] D. Garcìa-Fresnadillo, Y. Georgiadou, G. Orellana, A.M. Braun, E. Oliveros, Singlet-Oxygen $(1 \Delta \mathrm{g})$ Production by Ruthenium(II) complexes containing polyazaheterocyclic ligands in methanol and in water, Helv. Chim. Acta 79 (1996) 1222-1238, doi:http://dx.doi.org/10.1002/hlca.19960790428.

[11] E.R.D. Santos, J. Pina, T. Venâncio, C. Serpa, J.M.G. Martinho, R.M. Carlos, Photoinduced energy and electron-Transfer reactions by polypyridine ruthenium(II) complexes containing a derivatized perylene diimide, J. Phys. Chem. C 120 (2016) 22831-22843, doi:http://dx.doi.org/10.1021/acs. jpcc.6b06693.

[12] C. Mari, H. Huang, R. Rubbiani, M. Schulze, F. W??rthner, H. Chao, G. Gasser, Evaluation of perylene bisimide-based RuII and IrIII complexes as photosensitizers for photodynamic therapy, Eur. J. Inorg. Chem. 2017 (2017) 1745-1752, doi:http://dx.doi.org/10.1002/ejic.201600516.

[13] A.A. Abdel-shafi, P.D. Beer, R.J. Mortimer, F. Wilkinson, Photosensitized generation of singlet oxygen from vinyl linked benzo-crown-ether-bipyridyl ruthenium(II) complexes, J. Phys. Chem. A 104 (2000) 192-202, doi:http://dx. doi.org/10.1021/jp991876z.

[14] C. Girardot, G. Lemercier, J.C. Mulatier, C. Andraud, J. Chauvin, P.L. Baldeck, Novel 5-(oligofluorenyl)-1,10-phenanthroline type ligands: synthesis, linear and two-photon absorption properties, Tetrahedron Lett. 49 (2008) 17531758, doi:http://dx.doi.org/10.1016/j.tetlet.2008.01.080.

[15] J. Moreau, F. Lux, M. Four, J. Olesiak-Banska, K. Matczyszyn, P. Perriat, C. Frochot, P. Arnoux, O. Tillement, M. Samoc, G. Ponterini, S. Roux, G. Lemercier, A 5-(difluorenyl)-1,10-phenanthroline-based Ru(II) complex as a coating agent for potential multifunctional gold nanoparticles, Phys. Chem. Chem. Phys. 16 (2014) 14826-14833, doi:http://dx.doi.org/10.1039/c4cp01534g.

[16] G.T.P. Brancini, G.B. Rodrigues, M. de S.L. Rambaldi, C. Izumi, A.P. Yatsuda, M. Wainwright, J.C. Rosa, G.Ú.L. Braga, The effects of photodynamic treatment with new methylene blue $\mathrm{N}$ on the Candida albicans proteome, Photochem. Photobiol. Sci. 15 (2016) 1503-1513, doi:http://dx.doi.org/10.1039/ C6PP00257A.

[17] Y.S. El-Sayed, S.A. El-Daly, 3,4,9,10-Perylenetetracarboxylic acid derivatives, their spectral behavior and their chemical interaction with hydrated iron oxide nanopar, Chin. J. Chem. 28 (2010) 363-370, doi:http://dx.doi.org/10.1002/ cjoc.201090080.
[18] Z. Yu, Y. Wu, Q. Peng, C. Sun, J. Chen, J. Yao, H. Fu, Accessing the triplet state in heavy-atom-free perylene diimides, Chem.-A Eur. J. 22 (2016) 4717-4722, doi: http://dx.doi.org/10.1002/chem.201600300.

[19] H. Langhals, R. Ismael, Cyclophanes as model compounds for permanent dynamic aggregates-induced chirality with strong CD effects, Eur. J. Org. Chem. (1998) 1915-1917, doi:http://dx.doi.org/10.1002/(SICI)1099-0690 (199809)1998:9<1915:AID-EJOC1915>3.0.CO;2-1.

[20] P. Maia, E. Medeiros, B. Maria, L. Vega, H. Nunes, F.A. de Freitas, Synthesis and characterization of a perylene derivative and its application as catalyst for ethanol electro-oxidation, Chem. Pap. (2017), doi:http://dx.doi.org/10.1007| s11696-017-0344-z.

[21] H. Langhals, carboxylic imide structures as structure elements of high stability. Novel developments in perylene dye chemistry, Heterocycles 40 (1995) 477 500, doi:http://dx.doi.org/10.3987/REV-94-SR2.

[22] P.J.S. Maia, Synthesis, Spectroscopic Characterization, Photophysical Properties of N,-(5-amin-1, 10-phenanthroline) perylene-3, 4, 9, 10tetracarboximonoimide, IOSR Journal of Applied Chemistry 10 (2017) 13-20.

[23] M.T. Rawls, J. Johnson, B.A. Gregg, Coupling one electron photoprocesses to multielectron catalysts: towards a photoelectrocatalytic system, J. Electroanal Chem. 650 (2010) 10-15, doi:http://dx.doi.org/10.1016/j. jelechem.2010.09.016

[24] F. Yukruk, A.L. Dogan, H. Canpinar, D. Guc, E.U. Akkaya, Water-soluble green perylenediimide (PDI) dyes as potential sensitizers for photodynamic therapy, Org. Lett. 7 (2005) 2885-2887, doi:http://dx.doi.org/10.1021/ol050841g.

[25] I.T. Kato, R.A. Prates, C.P. Sabino, B.B. Fuchs, G.P. Tegos, E. Mylonakis, M.R Hamblin, M.S. Ribeiro, Antimicrobial photodynamic inactivation inhibits Candida albicans virulence factors and reduces in vivo pathogenicity, Antimicrob. Agents Chemother. 57 (2013) 445-451, doi:http://dx.doi.org/ 10.1128/AAC.01451-12.

[26] B.M. Soares, D.L. da Silva, G.R. Sousa, J.C.F. Amorim, M.A. de Resende, M Pinotti, P.S. Cisalpino, In vitro photodynamic inactivation of Candida spp. growth and adhesion to buccal epithelial cells, J. Photochem. Photobiol. B Biol. 94 (2009) 65-70, doi:http://dx.doi.org/10.1016/j. jphotobiol.2008.07.013.

[27] M. Wainwright, T. Maisch, S. Nonell, K. Plaetzer, A. Almeida, G.P. Tegos, M.R. Hamblin, Photoantimicrobials-are we afraid of the light? Lancet Infect. Dis. 17 (2017) e49-e55, doi:http://dx.doi.org/10.1016/S1473-3099(16)30268-7.

[28] L.P. Brion, S.E. Uko, D.L. Goldman, Risk of resistance associated with fluconazole prophylaxis: systematic review, J. Infect. 54 (2007) 521-529, doi:http://dx.doi.org/10.1016/j.jinf.2006.11.017.

[29] T. Abduljabbar, M. Al-Askar, M.K. Baig, Z.H. AlSowygh, S.V. Kellesarian, F. Vohra, Efficacy of photodynamic therapy in the inactivation of oral fungal colonization among cigarette smokers and non-smokers with denture stomatitis, Photodiagnosis Photodyn. Ther. 18 (2017) 50-53, doi:http://dx.doi org/10.1016/j.pdpdt.2017.01.182.

[30] B.P. Sullivan, DJ. Salmon, T.J. Meyer, Mixed phosphine 2,2'-Bipyridine complexes of ruthenium, Inorg. Chem. 17 (1978) 3334-3341, doi:http://dx. doi.org/10.1021/ic50190a006.

[31] E.C. Johnson, B.P. Sullivan, D.J. Salmon, S.A. Adeyemi, T.J. Meyer, Synthesis and properties of the chloro-bridged dimer [(bpy)2RuCl]22+ and its transient 3+ mixed-valence ion, Inorg. Chem. 17 (1978) 2211-2215, doi:http://dx.doi.org/ $10.1021 /$ ic50186a038.

[32] J. Rafael De Oliveira, V. Carlos De Castro, P. Das, G. Figueiredo Vilela, S. Esteves, A. Camargo, C. Antonio, T. Carvalho, A. Olavo, C. Jorge, L. Dias De Oliveira, Cytotoxicity of Brazilian plant extracts against oral microorganisms of interest to dentistry, BMC Complement. Altern. Med. 13 (2013) 1, doi:http://dx.doi.org/ 10.1186/1472-6882-13-208.

[33] F. Freire, A.C.B.P. Costa, C.A. Pereira, M. Beltrame, J.C. Junqueira, A.O.C. Jorge, Comparison of the effect of rose bengal- and eosin Y-mediated photodynami inactivation on planktonic cells and biofilms of Candida albicans, Lasers Med. Sci. 29 (2014) 949-955, doi:http://dx.doi.org/10.1007/s10103-013-1435-x.

[34] M.J. Frisch, G.W. Trucks, H.B. Schlegel, G.E. Scuseria, M.A. Robb, References [1], (2009) 2009.

[35] A.D. Becke, Density-functional thermochemistry. III. The role of exact exchange, J. Chem. Phys. 98 (1993) 5648-5652, doi:http://dx.doi.org/ $10.1063 / 1.464913$

[36] C. Lee, W. Yang, R.G. Parr, Development of the Colle-Salvetti correlation-energy formula into a functional of the electron density, Phys. Rev. B 37 (1988) 785 789, doi:http://dx.doi.org/10.1103/PhysRevB.37.785.

[37] P.J. Hay, W.R. Wadt, $A b$ initio effective core potentials for molecula calculations. Potentials for $\mathrm{K}$ to Au including the outermost core orbitals, J. Chem. Phys. 82 (1985) 299-310, doi:http://dx.doi.org/10.1063/1.448975.

[38] G. Schnurpfeil, J. Stark, D. Wöhrle, Syntheses of uncharged, positively and negatively charged 3,4,9,10-perylene-bis(dicarboximides), Dye. Pigm. 27 (1995) 339-350, doi:http://dx.doi.org/10.1016/0143-7208(94)00075-D.

[39] S. Asir, A.S. Demir, H. Icil, The synthesis of novel, unsymmetrically substituted, chiral naphthalene and perylene diimides: photophysical, electrochemical, chiroptical and intramolecular charge transfer properties, Dye. Pigm. 84 (2010) 1-13, doi:http://dx.doi.org/10.1016/j.dyepig.2009.04.014.

[40] D. Gosztola, M.P. Niemczyk, W. Svec, A.S. Lukas, M.R. Wasielewski, Excited doublet states of electrochemically generated aromatic imide and diimide radical anions, J. Phys. Chem. A 104 (2000) 6545-6551, doi:http://dx.doi.org/ $10.1021 /$ jp000706f.

[41] R.K. Dubey, M. Niemi, K. Kaunisto, K. Stranius, A. Efimov, N.V. Tkachenko, H. Lemmetyinen, Excited-state interaction of red and green perylene diimides 
with luminescent Ru(II) polypyridine complex, Inorg. Chem. 52 (2013) 97619773, doi:http://dx.doi.org/10.1021/ic400474b.

[42] A. Juris, V. Balzani, F. Barigelletti, S. Campagna, P. Belser, A. von Zelewsky, Ru(II) polypyridine complexes: photophysics, photochemistry, eletrochemistry, an chemiluminescence, Coord. Chem. Rev. 84 (1988) 85-277, doi:http://dx.doi. org/10.1016/0010-8545(88)80032-8.

[43] H. Dinalp, Z. Akar, C. Zafer, S. Li, Effect of side chain substituents on the electron injection abilities of unsymmetrical perylene diimide dyes, Dye. Pigm. 91 (2011) 182-191, doi:http://dx.doi.org/10.1016/j.dyepig.2011.03.022.
[44] C. Kirmaier, E. Hindin, J.K. Schwartz, I.Y. Sazanovich, J.R. Diers, K. Muthukumaran, M. Taniguchi, D.F. Bocian, J.S. Lindsey, D. Holten, Synthesis and excited-state photodynamics of perylene-bis(imide)-oxochlorin dyads. A charge-separation motif, J. Phys. Chem. B 107 (2003) 3443-3454, doi:http:// dx.doi.org/10.1021/jp0269423.

[45] Y. Suganuma, Y. Kowaka, N. Ashizawa, N. Nakayama, H. Goto, T. Ishimoto, U. Nagashima, T. Ueda, T. Yamanaka, N. Nishi, M. Baba, Mode-selective internal conversion of perylene, Mol. Phys. 109 (2011) 1831-1840, doi:http://dx.doi. org/10.1080/00268976.2011.593568. 